\title{
Свойства структуры и оптических фононов в нанокристаллах InSb, синтезированных в $\mathrm{Si}$ и $\mathrm{SiO}_{2}$
}

\author{
(C) И.Е. Тысченко ${ }^{1}$, Ж. Чжан ${ }^{2}$ \\ ${ }^{1}$ Институт фризики полупроводников им. А.В. Ржанова Сибирского отделения Российской академии наук, \\ 630090 Новосибирск, Россия \\ ${ }^{2}$ Новосибирский государственный университет, \\ 630090 Новосибирск, Россия \\ E-mail: tys@isp.nsc.ru
}

Поступила в Редакцию 4 июня 2020 г.

В окончательной редакции 7 сентября 2020 г.

Принята к публикации 18 сентября 2020 г.

\begin{abstract}
Интерес к созданию и изучению нанокристаллов InSb на основе кремния обусловлен необходимостью создания гибридных интегральных схем, объединяющих в себе элементы с различными функциональными свойствами. Локализация оптических фононов в кристаллах с пониженной размерностью может оказывать влияние как на оптические, так и на электрические свойства этих кристаллов. В данной работе проведен сравнительный анализ свойств оптических фононов в нанокристаллах $\mathrm{InSb}$, ионно-синтезированных в решетке $\mathrm{Si}$, а также в нанокристаллах $\mathrm{InSb}$ в пленках $\mathrm{SiO}_{2}$, созданных методами ионно-лучевого синтеза и радиочастотного магнетронного распыления. Свойства оптических фононов в нанокристаллах $\mathrm{InSb}$ объяснены с точки зрения влияния структурных свойств окружающей матрицы.
\end{abstract}

Ключевые слова: InSb, кремний, оксид кремния, нанокристаллы, синтез.

DOI: $10.21883 /$ FTP.2021.01.50388.9464

\section{1. Введение}

Интерес к созданию и изучению свойств нанокристаллов соединений $\mathrm{A}^{\mathrm{III}} \mathrm{B}^{\mathrm{V}}$, объединенных единой кремниевой платформой, вызван необходимостью создания гибридных интегральных схем, объединяющих элементы с различными функциональными свойствами [1-4]. Из всех соединений $\mathrm{A}^{\mathrm{III}} \mathrm{B}^{\mathrm{V}} \mathrm{InSb}$ обладает рекордными значениями подвижности электронов $\left(78000 \mathrm{~cm}^{2} \cdot \mathrm{B}^{-1} \cdot \mathrm{c}^{-1}\right)$ [5], что делает возможным использование этого полупроводника для создания двухзатворных транзисторов и увеличения быстродействия интегральных схем [6]. В InSb наблюдается большая величина спин-орбитального расщепления. Это делает его весьма привлекательным с точки зрения создания приборов полупроводниковой спинтроники и последующего применения в квантовой обработке информации [7]. InSb - прямозонный материал, что обеспечивает высокую квантовую эффективность излучения света и возможность использования его в целях создания оптической связи на кремнии. Ширина запрещенной зоны $\mathrm{InSb}$ при комнатной температуре составляет 0.17 эВ. При этом эффективная масса электронов и дырок имеет наименьшие значения $\left(0.015 m_{0}\right.$ и $0.39 m_{0}$ соответственно), а диэлектрическая постоянная имеет наибольшее значение по сравнению с другими полупроводниковыми материалами (17.8). Боровский радиус экситона в InSb составляет 65 нм. Это обеспечивает возможность наблюдения квантово-размерного эффекта в нанокристаллах $\mathrm{InSb}$ в широком диапазоне их размеров.

Создание гетероструктур InSb/Si эпитаксиальными методами сопряжено с целым рядом трудностей, связанных в первую очередь с большим рассогласованием их решеток (19\%). Это сопровождается в процессе роста генерацией высокой плотности дислокаций несоответствия и приводит к деградации электронных и оптических свойств гетероструктур. Поэтому поиск новых методов создания гетероструктур $\mathrm{InSb} / \mathrm{Si}$ остается весьма актуальным. В последнее время в литературе наибольшее число исследований свойств нанокристаллов $\mathrm{InSb}$ в матрицах кремния и оксида кремния связано с методами ионно-лучевого синтеза [8-18] и магнетронного распыления [19-23]. Особенность синтеза нанокристаллов InSb заключается в том, что из всех соединений $\mathrm{A}^{\mathrm{III}} \mathrm{B}^{\mathrm{V}}$ оно имеет самую низкую температуру плавления, равную $525^{\circ} \mathrm{C}$, что на несколько сотен градусов ниже температур, при которых обычно происходит синтез. Это означает, что рост нанокристаллов в матрицах кремния и оксида кремния происходит в расплавленном состоянии. Как результат, свойства сформированных нанокристаллов могут зависеть и от структурных свойств окружающей матрицы, и от метода их синтеза.

В кристаллах с пониженной размерностью становится весьма заметной роль оптических фононов. Их влияние на электрические и оптические свойства становится весьма ощутимым, когда размеры кристалла достигают нанометровых размеров. Локализация фононов влияет и на комбинационное рассеяние света (КРС), эффект, который лежит в основе метода, широко применяющегося на практике для характеризации полупроводниковых структур. В полярных нанокристаллах InSb частоты оптических фононов могут быть подвержены целому ряду факторов, затрудняющих их идентификацию. Наряду с эффектом размерного квантования, различного 
Таблица 1. Оптические фононы и структурные свойства нанокристаллов $\mathrm{InSb}$, синтезированных разными методами в матрицах $\mathrm{Si}$ и $\mathrm{SiO}_{2}$

\begin{tabular}{|c|c|c|c|c|c|c|}
\hline Матрица & Метод & $T,{ }^{\circ} \mathrm{C}$ & Мода & Частота КРС, см$^{-1}$ & Особенности структуры & Литература \\
\hline $\mathrm{Si},(100)$ & Ионный синтез & 1100 & $\frac{-}{\mathrm{LO}}$ & $\sim 189$ & $\begin{array}{l}\text { Нанокристаллы ориентированы } \\
\text { в соответствии с решеткой Si }\end{array}$ & {$[10,12,13]$} \\
\hline $\begin{array}{l}\text { Термически } \\
\text { выращенный } \mathrm{SiO}_{2}\end{array}$ & То же & $800-1100$ & $\begin{array}{l}\text { TO } \\
\text { LO }\end{array}$ & $\begin{array}{l}187 \\
195\end{array}$ & $\begin{array}{l}\text { Нанокристаллы имеют } \\
\text { хаотичную ориентацию }\end{array}$ & {$[17,18]$} \\
\hline Осажденный $\mathrm{SiO}_{2}$ & $\begin{array}{l}\text { Магнетронное } \\
\text { распыление }\end{array}$ & $300^{*}$ & $\begin{array}{l}\text { TO } \\
\text { LO }\end{array}$ & $\begin{array}{l}178.3 \\
188.0\end{array}$ & $\begin{array}{l}\text { Осажденная пленка имеет } \\
\text { низкую плотность }\end{array}$ & {$[20]$} \\
\hline Осажденный $\mathrm{SiO}_{2}$ & То же & $\begin{array}{c}900 \\
(\mathrm{RTA})\end{array}$ & $\begin{array}{l}\text { TO } \\
\text { LO }\end{array}$ & 180 & То же & [21] \\
\hline
\end{tabular}

Примечание. * Температура осаждения.

для продольной и поперечной оптической моды, в них возрастает вклад рассеяния на поверхностных фононах, возникающих на границе раздела нанокристалла с окружающей матрицей, а также на частоте Фрёлиха, напряжений, возникающих за счет различия постоянных решетки нанокристалла и матрицы или за счет разницы их коэффициентов термического расширения.

В данной работе мы проанализировали имеющиеся данные по свойствам нанокристаллов InSb (табл. 1), сформированных в матрицах $\mathrm{Si}$ и $\mathrm{SiO}_{2}$, методами магнетронного распыления и ионно-лучевого синтеза, и на основе сделанного анализа объяснили природу особенностей наблюдаемых свойств оптических фононов в нанокристаллах $\mathrm{InSb}$.

\section{2. Синтез нанокристаллов InSb в кремнии}

В настоящее время сопоставление структурных свойств нанокристаллов InSb в кремнии и свойств оптических фононов в них представляется возможным на основе данных, полученных методом ионно-лучевого синтеза. Метод ионного синтеза состоит из двух основных этапов: ионная имплантация больших доз ионов и последующий высокотемпературный отжиг. Имплантация ионов происходит в дозах, обеспечивающих концентрацию внедренных атомов на уровне нескольких атомных процентов и превышающей равновесный предел растворимости атомов в решетке. В процессе последующего высокотемпературного отжига происходит формирование зародыша новой фазы и последующий его рост за счет диффузионного стока атомов примеси. При этом ионный синтез нанокристаллов в кремнии сопровождается целым рядом процессов, обусловленных как имплантацией больших доз ионов в монокристаллическую матрицу, так и свойствами внедренных атомов в решетке кремния. Одним из факторов, сопутствующих имплантации больших доз тяжелых ионов, является генерация высокой плотности первичных смещений атомов решетки и аморфизация имплантированных слоев кремния. Это означает, что зарождение новой фазы может происходить в условиях ориентированной твердофазной кристаллизации окружающей матрицы кремния. При этом наличие остаточных дефектов в матрице Si после высокотемпературного отжига может иметь существенное влияние на структурные и оптические свойства формирующихся нанокристаллов соединений $\mathrm{A}^{\mathrm{III}} \mathrm{B}^{\mathrm{V}}$.

Особенностью ионного синтеза фазы InSb в кремнии являются высокая равновесная растворимость атомов индия $\left(\geq 1.8 \cdot 10^{18} \mathrm{~cm}^{-3} \quad[24]\right)$ и сурьмы $\left(\geq 5 \cdot 10^{19} \mathrm{~cm}^{-3}[25]\right)$ и большие значения коэффициентов диффузии [26,27]. Это означает, что при отжиге возможно сильное диффузионное перераспределение имплантированных атомов из области имплантации. Диффузионное перераспределение внедренных атомов In и $\mathrm{Sb}$ сопровождается изменением их локальной концентрации, которая определяет возможный механизм зарождения и роста фазы InSb. Этот эффект имеет значение не только для ионного синтеза соединения InSb, но и для соединений $\mathrm{A}^{\mathrm{III}} \mathrm{B}^{\mathrm{V}}$ вообще. Например, в работе [28] было высказано предположение, что препятствием на пути ионного синтеза сплошных захороненных слоев $\mathrm{GaAs}$ является диффузия атомов из имплантированного слоя к поверхности и высокая растворимость As. С другой стороны, растворимость атомов в решетке кремния сопровождается изменением их электрической активности. Это в свою очередь может быть причиной ускоренного взаимодействия атомов III и Vгрупп в решетке кремния. В работе [29] было показано, что наличие в решетке $\mathrm{Si}$ доноров приводит к увеличению растворимости индия. Методом измерения возмущения угловой корреляции было показано, что путем прямого взаимодействия донора и акцептора, находящихся в соседних замещающих положениях, происходит образование молекулярно-подобных кластеров соединений $\mathrm{A}^{\mathrm{III}} \mathrm{B}^{\mathrm{V}}$. Было обнаружено, что с ростом температуры доля и акцепторов, и доноров в замещающем положении падает. При этом наклон температурной зависимости одинаков и для индия, и для атома донора. Одновременно после высокотемпературного отжига наблюдалось 
формирование большой плотности мелких преципитатов с размерами $<5$ нм, которые имели ограненную форму с границами, параллельными направлениям $\langle 110\rangle$ матрицы кремния. Плотность преципитатов увеличивалась с ростом дозы индия в максимуме распределения. Анализ результатов показал, что формирование кластеров индия и донорных атомов происходит не только за счет взаимодействия атомов в положении замещения, но и за счет атомов, находящихся вблизи узла решетки. Формирование преципитатов происходит при температуре $1100^{\circ} \mathrm{C}$, которая превышает температуру плавления соединений $\mathrm{A}^{\mathrm{III}} \mathrm{B}^{\mathrm{V}}$ на основе индия. По мнению авторов [29], это приводит к разрыву связей между донором и акцептором и формированию преципитатов с преимущественно металлическим составом (избытком индия). Длительный отжиг при температурах ниже температуры плавления может также приводить к ориентированному росту нанокластеров, но стехиометрического состава. Согласно полученным результатам [29], для каждого соединения $\mathrm{A}^{\mathrm{III}} \mathrm{B}^{\mathrm{V}}$ существует „концентрационно-температурное окно“, в котором может происходить устойчивый рост зародыша новой фазы. Стабильность зародыша зависит как от напряжения химических связей между донором и акцептором, так и от рассогласования решеток.

Структурные и оптические свойства пленок кремния, в которых методом ионно-лучевого синтеза были сформированы нанокристаллы InSb, исследовались в работах $[10,12,13]$. Исходные образцы монокристаллического $\mathrm{Si}$ с ориентацией (100) размером $1 \times 1 \mathrm{~cm}^{2}$ были последовательно имплантированы ионами $\mathrm{Sb}^{+}$и $\mathrm{In}^{+}$с энергией 350 кэВ дозами $3.5 \cdot 10^{16} \mathrm{~cm}^{-2}$. Использованные параметры ионов позволяли получить пространственное распределение атомов индия и сурьмы на глубине от 120 до 150 нм. С целью предотвращения аморфизации решетки кремния, имплантация проводилась при температуре $500^{\circ} \mathrm{C}$. Постимплантационный отжиг проводили при температуре $900-1100^{\circ} \mathrm{C}$ либо в условиях быстрого термического отжига в течение 3 мин, либо в обычной печи в течение 30 или 60 мин в атмосфере аргона. После отжига при температуре $1100^{\circ} \mathrm{C}$ в течение 30 мин в кремнии наряду с дислокационными петлями и микродвойниками наблюдались мелкие нанопреципитаты, размеры которых варьировались в довольно широком диапазоне, от 2 до $50 \mathrm{Hм}$, а основная их доля имела размеры от $\sim 10$ до $\sim 30$ нм. Увеличение длительности отжига с 30 до 60 мин приводило к кардинальному улучшению структуры имплантированных слоев. Дислокации несоответствия при этом практически полностью отжигались, а нанокластеры приобретали кристаллическую структуру и имели ограненную форму.

В спектрах КРС, возбуждаемых излучением полупроводникового лазера с длиной волны 473 нм от образцов, имплантированных ионами $\mathrm{Sb}^{+}$и $\mathrm{In}^{+}$и отожженных в различных условиях, также происходили изменения с ростом длительности отжига, которые коррелировали с данными электронной микроскопии. Сразу после имплантации ионов $\mathrm{In}^{+}$и $\mathrm{Sb}^{+}$в спектре доминировал пик
Таблица 2. Зависимость параметров пиков КРС при разных временах отжига при $1100^{\circ} \mathrm{C}$ кремния, имплантированного ионами $\mathrm{In}^{+}$и $\mathrm{Sb}^{+}[10,12,13]$

\begin{tabular}{c|c|c|c}
\hline \multirow{2}{*}{$\begin{array}{c}\text { Время } \\
\text { отжига }\end{array}$} & $\begin{array}{c}\mid 3 \\
\text { Параметр пика КРС } \\
\text { КРС, см }\end{array}$ & $\begin{array}{c}\text { Паксимума } \\
\text { КРС, см }\end{array}$ & $\begin{array}{c}\text { Ширина пика } \\
\text { КРенсивность, } \\
\text { отн. ед. }\end{array}$ \\
\hline \multirow{3}{*}{3 мин } & 189.5 & 8.57 & 1804 \\
30 мин & 199.0 & 4.25 & 402 \\
& 188.9 & 8.80 & 1543 \\
60 мин & 198.4 & 4.10 & 302 \\
& 188.9 & 9.95 & 1398 \\
& 199.2 & 3.99 & 247
\end{tabular}

рассеяния на частоте $516 \mathrm{~cm}^{-1}$, который соответствовал рассеянию на частоте локализованных оптических фононов в кристаллической матрице кремния. После отжига при температуре $1100^{\circ} \mathrm{C}$ в течение 3 мин в спектре КРС наряду с увеличением интенсивности пика рассеяния на частоте оптических фононов в кремнии, свидетельствующем об упорядочении кремниевой решетки, появлялась полоса рассеяния на частоте $189 \mathrm{~cm}^{-1}$, которая соответствовала рассеянию на продольных оптических фононах (LO) в кристаллической решетке InSb. В спектре не было четкого проявления пика, связанного с поперечным оптическим фононом, а в высокочастотной области LO-моды наблюдается асимметричное плечо рассеяния. Параметры пиков КРС, полученных из разложения экспериментальных спектров, предоставленных авторами работ $[10,12,13]$, на составляющие пики распределения Гаусса, представлены в табл. 2. Из табл. 2 видно, что наряду с основным максимумом на частоте $189.5 \mathrm{~cm}^{-1}$ наблюдается менее интенсивный пик на частоте $199.0 \mathrm{~cm}^{-1}$, природа которого требует подробного анализа.

В спектре образца, отожженного в течение 3 мин при $1100^{\circ} \mathrm{C}$, были видны также слабые сигналы на частотах $\sim 115$ и $\sim 150 \mathrm{~cm}^{-1}$, которые авторы [10,12,13] связывают с рассеянием на TO- и LO-фононах кристаллической сурьмы. Для объемных образцов $\mathrm{Sb}$ частоты LO- и ТО-фононов составляют 113 и $155 \mathrm{~cm}^{-1}$ [30]. Эти полосы исчезают при увеличении времени постимплантационной термической обработки до 30 мин, что может быть обусловлено растворением нанопреципитатов сурьмы за счет роста размеров нанокристаллов InSb. Увеличение длительности отжига до 30 мин не приводит к изменению частотного положения пиков, обусловленных рассеянием на оптических фононах в матрице InSb, a лишь сопровождается изменением их ширины и интенсивности пиков. При этом ширина низкочастотного пика $\left(\sim 189 \mathrm{~cm}^{-1}\right)$ растет, а его интенсивность падает. В случае высокочастотного пика $\left(\sim 199 \mathrm{~cm}^{-1}\right)$ уменьшаются и ширина, и интенсивность. Увеличение длительности отжига до 60 мин сохраняет эту зависимость. 
Итак, в спектре оптических фононов нанокристаллов $\mathrm{InSb}$, ионно-синтезированных в матрице кремния, доминирует полоса рассеяния с максимумом на частоте LO-моды $\sim 189 \mathrm{~cm}^{-1}$. Частотное положение этой линии не зависит от длительности отжига при температуре $1100^{\circ} \mathrm{C}$. С ростом времени отжига происходит лишь снижение интенсивности этой полосы и увеличение ее ширины, что может свидетельствовать об увеличении разброса нанокристаллов по размерам. Что касается пика на частоте $\sim 199 \mathrm{~cm}^{-1}$, то его параметры в зависимости от времени отжига ведут себя несколько иначе. Это может быть связано с разными причинами. Одной из таких причин может быть наличие напряженной фазы InSb, которая формируется при быстрых отжигах. Напряжения в нанокристаллах могут возникать, с одной стороны, из-за разницы постоянных решетки кремния и InSb. Эта разница составляет $\sim 19 \%$. В общем случае напряжения, обусловленные рассогласованием решеток, являются негидростатическими. Это должно приводить к расщеплению основной моды в спектрах КРС. С ростом размера нанокристаллов эти напряжения релаксируют. Поэтому появления высокочастотного плеча в спектре продольной оптической моды можно было бы связать с дисперсией напряжений по размерам нанокристаллов. Действительно, с увеличением длительности отжига и соответствующим ростом размеров нанокристаллов интенсивность высокочастотного пика $199 \mathrm{~cm}^{-1}$ затухает. Однако отсутствие расщепления пиков в спектрах КРС свидетельствует, скорее, о гидростатическом характере деформаций в нанокристаллах малых размеров.

В случае эндотаксиального роста нанокристаллов $\mathrm{InSb}$ величина и характер деформаций решетки могут определяться, скорее, различием плотностей жидкой и твердой фаз InSb. При температуре отжига $1100^{\circ} \mathrm{C}$, которая на $575^{\circ} \mathrm{C}$ превышает температуру плавления $\mathrm{InSb}$, рост нанокристалла происходит в жидком состоянии. При кристаллизации расплавленного преципитата $\mathrm{InSb}$ за счет охлаждения должна измениться его плотность, что в свободном состоянии связано с изменением объема решетки InSb. Однако в том случае, когда нанокристалл растет внутри матрицы кремния, его расширение ограничено коэффициентом термического расширения (КТР) $\mathrm{Si}$, поскольку КТР кремния составляет $2.3 \cdot 10^{-6} \mathrm{~K}^{-1}$, a KTP InSb в жидкой и твердой фазах составляют $3.48 \cdot 10^{-5}$ и $5.5 \cdot 10^{-6} \mathrm{~K}^{-1}$ соответственно. Это означает, что нанокристалл $\mathrm{InSb}$ в матрице $\mathrm{SiO}_{2}$ будет сжат. Максимальное значение деформаций, обусловленных различием плотностей антимонида индия в жидком и твердом состояниях, при условии их гидростатичности можно оценить следующим образом:

$$
\frac{\Delta a}{a_{0}}=-\frac{\sqrt[3]{\frac{1}{N_{s}}}-\sqrt[3]{\frac{1}{N_{l}}}}{\sqrt[3]{\frac{1}{N_{l}}}}
$$

где $a_{0}-$ расстояние между атомами в жидкой фазе, $\Delta a$ - разница расстояний между атомами в твердой и жидкой фазах $\mathrm{InSb}, N_{s}=1.63 \cdot 10^{22} \mathrm{~cm}^{-3}-$ плотность атомов в жидкой фазе InSb, $N_{l}=1.45 \cdot 10^{22} \mathrm{~cm}^{-3}-$ плотность атомов в твердой фазе InSb. После подстановки числовых значений в выражение (1), величина деформаций получается равной -0.028. Связь между частотой смещения моды LO-фононов в InSb и величиной гидростатических деформаций была получена в работе [31]:

$$
\begin{aligned}
\omega_{\mathrm{LO}} & =190.7+5.11 P-0.3 P^{2} \\
& =190.7-668\left(\Delta a / a_{0}\right),
\end{aligned}
$$

где частота продольного $\omega_{\mathrm{LO}}$ оптического фонона выражена в $\mathrm{cm}^{-1}$, давление $P$ выражено в ГПа. Согласно выражению (2), величине деформаций -0.028 соответствует $\omega_{\mathrm{LO}}=209.4 \mathrm{~cm}^{-1}$. Эта величина на $10 \mathrm{~cm}^{-1}$ больше значения, наблюдаемого экспериментально. Наблюдаемое различие в смещении полос за счет деформаций может быть обусловлено влиянием квантово-размерного эффекта в мелких нанокристаллах. В данном случае величина низкочастотного сдвига за счет квантоворазмерного эффекта должна составлять $\sim 10 \mathrm{~cm}^{-1}$. Согласно расчетам, выполненным в работах $[17,18]$, такой сдвиг частоты LO-моды может быть достигнут лишь в нанокристаллах с размером $\sim 1$ нм. Низкая термическая стабильность нанокристаллов с такими размерами является причиной уменьшения интенсивности пика КРС на частоте $\sim 199 \mathrm{~cm}^{-1}$ при длительных отжигах.

Согласно результатам, полученным в работах $[10,12,13]$, в спектрах КРС доминирует пик LO-фононов на частоте, соответствующей ее значению в объемном монокристалле InSb. Это означает, что подавляющая доля закристаллизовавшегося объема $\mathrm{InSb}$ является все-таки недеформированной. Причина такого эффекта может заключаться в том, что при ионно-лучевом синтезе постоянные решетки $\mathrm{InSb}$ и $\mathrm{Si}$ могут быть адаптированы друг к другу за счет замены различных атомов в узлах решетки в присутствии неравновесных точечных дефектов. Соотношения для согласованного роста решеток с большим несоответствием было получено в работе [32]. Первое соотношение определяет значение постоянной решетки для аксиального согласования и имеет вид: $p a_{\text {Sub }} / m^{1 / 2}=q a_{\text {film }} / n^{1 / 2}$, где $p$ и $q-$ целые числа, $a_{S u b}$ - постоянная решетки подложки (полупроводника), $a_{\text {film }}-$ постоянная решетки эпитаксиальной пленки, $m^{1 / 2}, n^{1 / 2}=\left(h^{2}+k^{2}+l^{2}\right)^{1 / 2}-$ длина соответствуюшего единичного вектора решетки с координатами $h, k, l$. В терминах межплоскостных расстояний выражение аксиального согласования будет иметь вид: $p d_{h k l}($ substrate $)=q d_{h k l}($ film $)$. Условие аксиального согласования позволяет определить межплоскостное расстояние матрицы, оптимальное для последующего эпитаксиального роста новой фазы. Это соотношение в случае эпитаксиального роста не является исчерпывающим и, кроме направления роста, необходимо определить наиболее подходящую плоскость роста. Это позволяет создать условия 
для большого количества планарно-согласованных плоскостей. Это соответствие описывается уравнением согласования решеток в плоскости поперечного сечения. Оно имеет вид: $\left(n_{1 h} d_{1 h}\right)^{2}=\left(n_{2 h} d_{2 h}\right)^{2}+\left(n_{2 v} d_{2 v}\right)^{2}$, где $n_{1 h}, n_{2 h}, n_{2 v}$ - целые числа, определяемые также, как и в выражении для аксиального согласования (см. выше), здесь индекс „1“ относится к материалу с фиксированной ориентацией, а индекс „2“ - к материалу с изменяемой ориентацией; $d_{1 h}, d_{2 h}$ и $d_{2 v}-$ межплоскостные расстояния, найденные с использованием выражения для аксиального согласования решеток. В соответствии с полученными соотношениями большие различия решеток широкого класса соединений могут быть согласованы.

При ионно-лучевом синтезе согласованный рост облегчен генерацией и последующей рекомбинацией при отжиге неравновесных точечных дефектов. В пользу ориентированного роста нанокристаллов $\mathrm{InSb}$, синтезированных в матрице $\mathrm{Si}$, свидетельствует их ограненная форма $[10,12,13]$. Другим свидетельством ориентированного роста нанокристаллов InSb является наблюдение в спектрах КРС лишь пика рассеяния на продольной оптической моде $\left(\sim 189 \mathrm{~cm}^{-1}\right)$. Пик поперечных оптических фононов на частоте $\sim 179 \mathrm{~cm}^{-1}$ отсутствует, в то время как в разориентированных нанокристаллах $\mathrm{InSb}$, как правило, наблюдаются обе оптические моды (будет показано в следующем разделе). Дело в том, что в решетке кремния с ориентацией (100) поперечные оптические фононы запрещены правилами отбора, и наблюдаются лишь продольные оптические фононы. Поэтому отсутствие в спектре КРС нанокристаллов InSb поперечной оптической моды возможно лишь в том случае, если нанокристаллы лежат точно в плоскости (100) и их решетка согласована с решеткой кремния.

\section{3. Синтез нанокристаллов InSb в оксиде кремния}

\section{1. Ионно-лучевой синтез нанокристаллов InSb в $\mathrm{SiO}_{2}$}

По сравнению с ионным синтезом в кремнии, ионный синтез нанокристаллов InSb в оксиде кремния имеет целый ряд особенностей, обусловленных в первую очередь низкой растворимостью индия и сурьмы в узлах матрицы $\mathrm{SiO}_{2}$, а также низкими значениями их коэффициентов диффузии. В оксиде кремния значения коэффициентов диффузии элементов III и V групп также различаются и в сильной мере определяются их химическим состоянием в матрице $\mathrm{SiO}_{2}$. Элементы III группы могут находиться в трехвалентном или одновалентном состояниях, когда они образуют связи с атомами кислорода [33,34]. В трехвалентном состоянии атомы III группы (In и Ga) замещают атомы кремния и являются четырежды координированными атомами кислорода (рис. 1,a). В этом случае они практически неподвижны. В одновалентном состоянии атомы III группы в матрице $\mathrm{SiO}_{2}$ существуют $a$
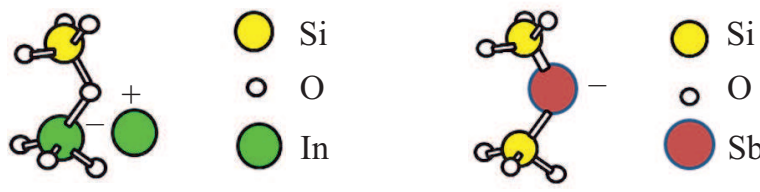

Рис. 1. Схематическое изображение положения атомов в матрице $\mathrm{SiO}_{2}: a$ - In в положении замещения атома $\mathrm{Si}$ и в виде одновалентного междоузлия; $b-\mathrm{Sb}$ в положении замещения атома $\mathrm{O}$.

в качестве положительно заряженного междоузлия и связаны с трехвалентным атомом в замещающем положении (рис. 1,a). В этом состоянии атомы, например In, обладают достаточно высокой диффузионной способностью с энергией активации $\sim 2$ эВ [33]. Именно этот механизм считается определяющим процесс испарения индия из оксида кремния при высоких температурах [33]. Для элементов III группы в оксиде кремния существует третье состояние, в котором они обладают высокой диффузионной способностью, а именно в виде нейтрального комплекса (например, InOH), который формируется при отжиге в атмосфере водорода.

Атомы V группы в матрице $\mathrm{SiO}_{2}$ также могут занимать узловые положения, замещая либо атом кремния, либо атом кислорода [35,36]. В условиях присутствия в матрице $\mathrm{SiO}_{2}$ избыточного кислорода атомы $\mathrm{Sb}$ находятся в положении замешения атомов кремния, образуя $\mathrm{Sb}-\mathrm{O}$ связи в виде комплексов $\equiv \mathrm{Sb}^{\bullet}-\mathrm{O}-\mathrm{Si} \equiv$ или $\equiv \mathrm{Sb}=\mathrm{O} . \mathrm{Si} \equiv$. В этом случае атомы сурьмы могут быть легко вытеснены атомами кремния из узлового положения, и могут мигрировать с коэффициентом диффузии $D_{\mathrm{Sb}}=3.7 \cdot 10^{-11} \exp (-1.32$ эВ $/ k T)\left(\mathrm{cм}^{2} / \mathrm{c}\right)[36]$. В случае дефицита кислорода атомы сурьмы в замещающем положении образуют $\mathrm{Sb}-\mathrm{Si}-$ связи, т. е. находятся в положении замещения кислорода (рис. $1, b)$. В этом положении они практически неподвижны. Таким образом, атомы In и $\mathrm{Sb}$, находясь в замещающих положениях в матрице $\mathrm{SiO}_{2}$, обладают совершенно противоположными свойствами. Это может быть лимитирующим фактором при формировании зародыша фазы InSb.

Ионный синтез нанокристаллов InSb в захороненном слое $\mathrm{SiO}_{2}$ и свойства оптических фононов в зависимости от температуры отжига изучались в работах [16-18]. Сначала ионы $\mathrm{In}^{+}$и $\mathrm{Sb}^{+}$с энергией 200 кэВ дозой $8 \cdot 10^{15} \mathrm{~cm}^{-2}$ внедрялись в термически выращенные пленки $\mathrm{SiO}_{2}$ толщиной 300 нм. Параметры ионов позволяли создать профили атомов In и $\mathrm{Sb}$ в виде распределения Гаусса с максимумом на глубине $\sim 110$ нм от поверхности пленки $\mathrm{SiO}_{2}$ и концентрацией $\sim 1.2 \cdot 10^{21} \mathrm{~cm}^{-3}$. Затем на пластину с имплантированной пленкой $\mathrm{SiO}_{2}$ была перенесена пленка кремния толщиной $\sim 500$ нм водородно-индуцированным методом с использованием технологии DeleCut [37]. Последующий высокотемпературный отжиг облученных образцов про- 
водился при температуре $500-1100^{\circ} \mathrm{C}$ в атмосфере азота в течение 30 мин. В реализованной схеме эксперимента при отжиге было минимизировано поступление извне в пленку $\mathrm{SiO}_{2}$ избыточного кислорода при высокотемпературном отжиге. В этих условиях, с одной стороны, были предотвращены сток к поверхности и последующее испарение из $\mathrm{SiO}_{2}$ индия, а с другой - была обеспечена низкая диффузионная способность сурьмы.

В работе [16] методом резерфордовского обратного рассеяния (РОР) было обнаружено немонотонное диффузионное перераспределение атомов индия и сурьмы при температурах отжига $800-1100^{\circ} \mathrm{C}$. После отжига при $800^{\circ} \mathrm{C}$ наблюдалось диффузионное уширение суммарного профиля атомов In и Sb. Соотношение между шириной профилей неотожженного и отожженного образцов можно описать выражением $\left(\Delta R_{p}^{\prime}\right)^{2}=\left(\Delta R_{p}\right)^{2}+2 D t$, где $\Delta R_{p}$ - ширина на полувысоте профиля распределения ионов до отжига, $\Delta R_{p}^{\prime}-$ ширина на полувысоте профиля распределения ионов после отжига, $D$ - коэффициент диффузии, $t-$ время отжига. Оцененное из экспериментальных профилей [16] значение коэффициента диффузии при $800^{\circ} \mathrm{C}$ составляет $1.9 \cdot 10^{-15} \mathrm{~cm}^{2} / \mathrm{c}$. Это близко к коэффициенту диффузии индия, который при температуре $800^{\circ} \mathrm{C}$ равен $2.8 \cdot 10^{-15} \mathrm{~cm}^{2} / \mathrm{c}$. Иными словами, диффузионное расширение суммарного профиля имплантированных атомов в этом случае, по-видимому, определяется диффузией атомов индия, а небольшое подавление диффузии индия может быть обусловлено его взаимодействием с атомами сурьмы в области имплантации. Действительно, электронно-микроскопические исследования на поперечном срезе обнаружили формирование наночастиц с размерами от 5 до 15 нм в области имплантации ионов, часть из которых имела кристаллическую структуру с межплоскостным расстоянием $0.392-0.395$ нм. Это значение превышает расстояние между плоскостями (111) в решетке InSb, которое составляет $0.374 \mathrm{Hм}$.

Отжиг при температуре $900^{\circ} \mathrm{C}$ приводил к кардинальному изменению суммарного профиля атомов. В этом случае он имеет тримодальную форму с максимумами в области средних пробегов ионов, вблизи верхней границы раздела $\mathrm{Si} / \mathrm{SiO}_{2}$ и в слое $\mathrm{SiO}_{2}$ на глубине приблизительно удвоенного пробега ионов (рис. 2,a). Глубокое проникновение атомов в работе [16] связывается с диффузией индия в комплексе InOH. Структурный анализ методом просвечивающей электронной микроскопии на поперечном срезе обнаружил формирование наночастиц, распределенных практически по всей толщине слоя $\mathrm{SiO}_{2}$. В приповерхностной области плотность наночастиц составляла $\sim 5 \cdot 10^{11} \mathrm{~cm}^{-2}$ при средних размерах $\sim 12$ нм. В области, соответствующей среднему проективному пробегу ионов $\mathrm{In}^{+}$и $\mathrm{Sb}^{+}$, их плотность была на порядок величины меньше, а средние размеры не превышали 10 нм. Большая часть наночастиц в этих областях имела кристаллическую структуру с межплоскостным расстоянием решетки 0.392-0.395 нм.
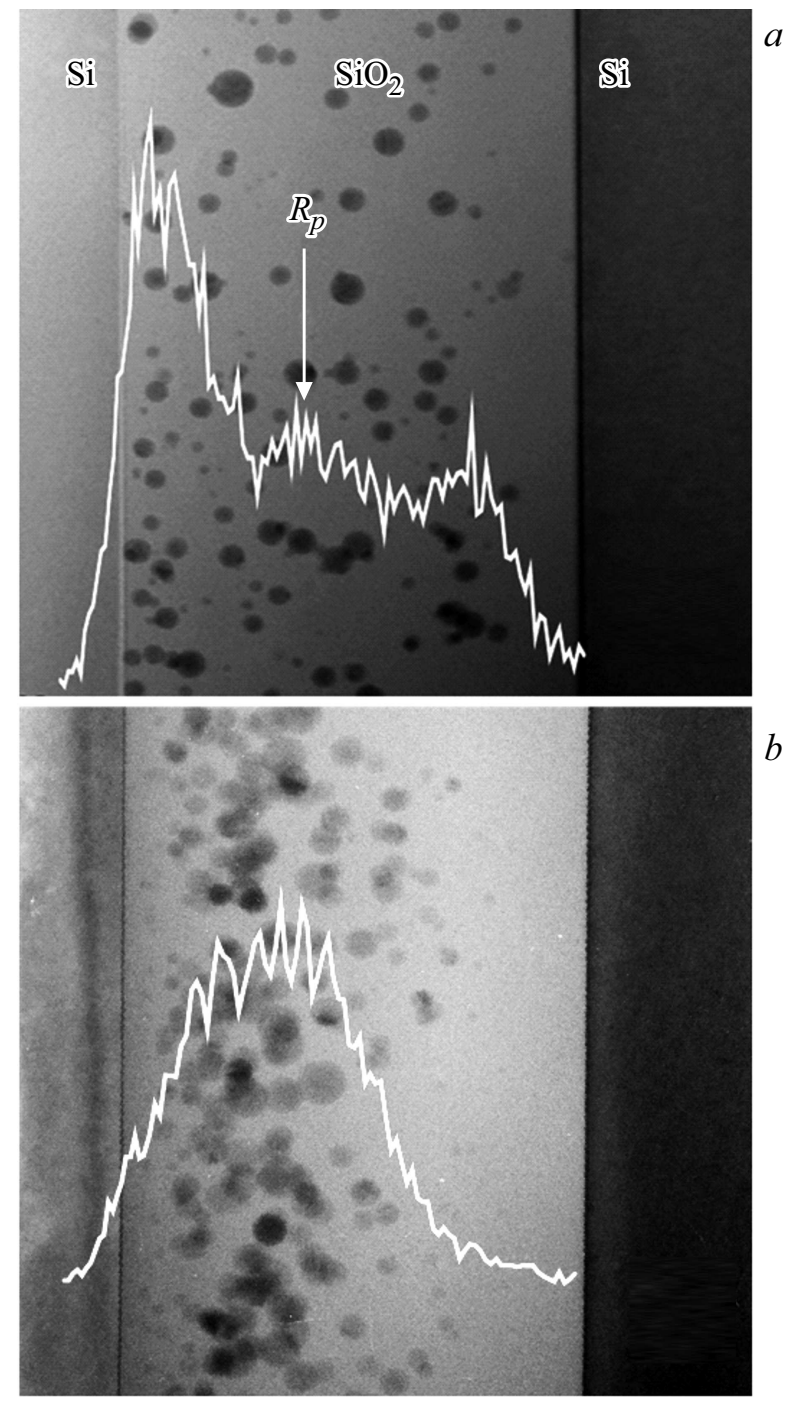

Рис. 2. Электронно-микроскопическое изображение на поперечном срезе структуры кремний-на-изоляторе с нанокристаллами $\mathrm{InSb}$ в захороненном слое $\mathrm{SiO}_{2}$ и профили распределения имплантированных атомов $\mathrm{In}$ и $\mathrm{Sb}$ после отжига при $900(a)$ и $1100^{\circ} \mathrm{C}(b)$ в течение 30 мин в потоке паров $\mathrm{N}_{2}$ [16].

В третьей области (на глубине $\geq 2 R_{p}$ ) наночастицы имели в основном некристаллическую структуру.

Увеличение температуры отжига до $\sim 1100^{\circ} \mathrm{C}$ приводило к тому, что суммарный профиль атомов In и $\mathrm{Sb}$ вновь принимал форму распределения Гаусса. При этом ширина суммарного распределения атомов после отжига на 20\% превышала ширину профиля, измеренного сразу после имплантации. Из анализа экспериментальных профилей [16] получено значение коэффициента диффузии имплантированных атомов $D=8.2 \cdot 10^{-16} \mathrm{~cm}^{2} / \mathrm{c}$. Коэффициент диффузии атомов $\mathrm{Sb}$ при температуре $1100^{\circ} \mathrm{C}$ составляет $5.1 \cdot 10^{-16} \mathrm{~cm}^{-2}$, а коэффициент диффузии In $\sim 3.2 \cdot 10^{-13} \mathrm{~cm}^{2} / \mathrm{c}$. Это указывает на то, что при высоких температурах пространственное распределение атомов индия зависит от диффузионных свойств сурьмы, 
которое в свою очередь определяется их относительным расположением в решетке $\mathrm{SiO}_{2}$. После отжига при температуре $1100^{\circ} \mathrm{C}$ формирование наночастиц наблюдалось лишь на глубине, прилегающей к области имплантации ионов (рис. 2,b). В этом случае они имели четкий контраст и кристаллическую структуру с межплоскостным расстоянием, равным 0.374 нм, что соответствовало ориентации (111) в решетке InSb. При этом максимуму распределения наночастиц по размерам соответствует величина $12.2 \mathrm{HM}$, а их плотность составляет $\sim 3 \cdot 10^{11} \mathrm{~cm}^{-2}$.

Заметим, что наночастицы во всех случаях имели сферическую форму и не имели четкой огранки, связанной с преимущественной ориентацией. Это указывает на отсутствие упорядочения нанокристаллов $\mathrm{InSb}$, формирующихся в матрице $\mathrm{SiO}_{2}$.

В спектрах КРС, возбужденных излучением Ar-лазера с длиной волны 514.5 нм и соответствующих описанным выше условиям эксперимента, после отжига при $800^{\circ} \mathrm{C}$ наблюдалась широкая полоса рассеянии в области частот от $\sim 180$ до $\sim 200 \mathrm{~cm}^{-1}$, природа которой может быть обусловлена рассеянием на оптических фононах связей In-Sb в кристаллической матрице InSb $[17,18]$. Увеличение температуры отжига приводило к увеличению интенсивности полосы КРС и четкому проявлению двух пиков на частотах около 187 и $195 \mathrm{~cm}^{-1}$. Смещения пиков по частоте при этом не наблюдалось. Природа этих полос ассоциируется с поперечной (TO) и продольной (LO) модами оптического фонона в матрице InSb, смещенными в высокочастотную область на 7.3 и $4.3 \mathrm{~cm}^{-1}$ соответственно [38]. После разложения экспериментальных спектров на составляющие пики в форме распределения Гаусса было обнаружено, что после отжига при температуре $<1000^{\circ} \mathrm{C}$ в спектрах КРС доминирует низкочастотная ТО-подобная мода, а после отжига при $1000-1100^{\circ} \mathrm{C}$ интенсивности ТОи LO-подобных мод становятся сопоставимыми. При этом ширина ТО-моды с ростом температуры падает, а LO-моды практически не зависит от температуры отжига. В экспериментах $[17,18]$ расщепление LO-TO-моды оптического фонона составляло $8 \mathrm{~cm}^{-1}$, что на $3 \mathrm{~cm}^{-1}$ меньше, чем его значение в объемном монокристалле InSb.

Полученные в работах $[17,18]$ спектры КРС были проанализированы с точки зрения влияния квантоворазмерного эффекта, механических напряжений в нанокристаллах, частоты поверхностного фонона, а также рассеяния на частоте, соответствующей растянутым анион-катионным модам на поверхности полярных сферических нанокристаллов.

С целью учета вклада квантово-размерного эффекта в смещение частоты оптического фонона в нанокристаллах InSb в работах $[17,18]$ были рассчитаны ТO и LO колебательные моды в зависимости от размера нанокристалла в рамках модели пространственной локализации фонона [38-40]. Расчеты показали, что для нанокристаллов с радиусом < 10 нм наблюдается

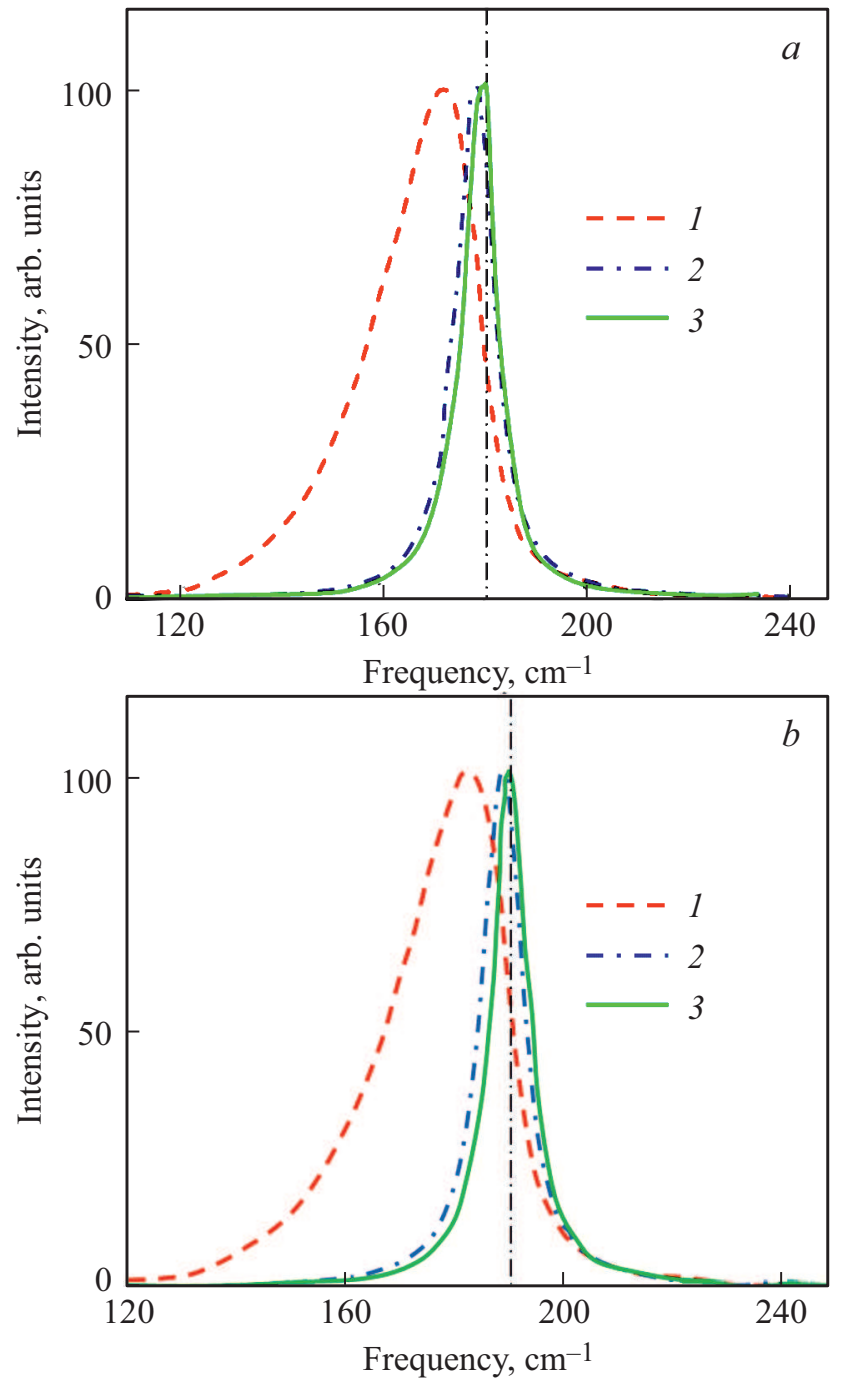

Pис. 3. ТО- $(a)$ и LO-колебательные моды $(b)$ в сферических нанокристаллах InSb диаметром 1, 3 и $10 \mathrm{HM}$, рассчитанные в рамках модели пространственной локализации фонона $[17,18]$. Вертикальными пунктирными линиями показаны частоты ТOи LO-моды в объемном монокристалле $\mathrm{InSb}$.

асимметричное уширение линий оптических фононов и низкочастотное смещение их максимума. Для нанокристаллов с радиусом > 10 нм частоты TO- и LO-мод практически совпадают с их значениями в матрице объемного монокристаллического InSb (рис. 3). При этом величина расщепления моды оптического фонона не зависит от размера нанокристалла и, как и в объемном монокристалле InSb, составляет $11 \mathrm{~cm}^{-1}$.

Вклад деформаций в смещение частоты оптических фононов в работах $[17,18]$ был сделан по сдвигу самой высокочастотной линии в спектре оптических фононов $\mathrm{InSb}$, т.е. частоты продольного оптического фонона $\omega_{\mathrm{LO}}$, с использованием выражения (2). Частота продольного оптического фонона меньше всего подвержена искажению за счет вклада других колебаний, в то время как наблюдение высокочастотного смещения 
поперечной оптической моды может быть искажено за счет вклада рассеяния на поверхностных фононах, резонанса Фрёлиха и др. Оцененная величина деформации составляла -0.0064 , что может быть достигнуто при гидростатическом сжатии 10 кбар [31]. При этом частоте ТО-фонона должна соответствовать величина $\sim 184.5 \mathrm{~cm}^{-1}$, что на $\sim 2.5 \mathrm{~cm}^{-1}$ меньше экспериментально наблюдаемого значения.

Пленку $\mathrm{SiO}_{2}$ с нанокристаллами $\mathrm{InSb}$, размеры которых много меньше длины волны падающего света, а плотность достаточно высока, можно рассматривать как среду с некоторой эффективной диэлектрической постоянной. В такой среде можно наблюдать различные резонансы, в том числе и резонанс на частоте Фрёлиха [41]. Резонанс Фрёлиха наблюдается на частотах, соответствующих растянутым анион-катионным модам на поверхности сферических нанокристаллов, и не зависит от размера частицы, на которой происходит рассеяние [42]:

$$
\omega_{F}=\left(\frac{\omega_{\infty} \omega_{\mathrm{LO}}^{2}+2 \varepsilon_{\mathrm{SiO}_{2}} \omega_{\mathrm{TO}}^{2}}{\varepsilon_{\infty}+2 \varepsilon_{\mathrm{SiO}_{2}}}\right)^{1 / 2},
$$

где $\varepsilon_{\infty}=15.9, \varepsilon_{\mathrm{SiO}_{2}}=3.9$. После подстановки численных значений в выражение (3) для системы $\mathrm{SiO}_{2} / \mathrm{InSb}$ была получена частота Фрёлиха $\omega_{F}=187 \mathrm{~cm}^{-1}$, что в точности совпадает с положением ТО-подобного пика в экспериментально наблюдаемых спектрах $[17,18]$.

Итак, анализ экспериментальных данных показал, что нанокристаллы InSb, ионно- синтезированные в матрице $\mathrm{SiO}_{2}$, обладают сферической формой, разориентированы друг относительно друга. В спектрах КРС указанных нанокристаллов наблюдаются две линии фононов, смещенные относительно известных линий ТОи LO-фонона в матрице монокристалла InSb на 7.3 и $4.3 \mathrm{~cm}^{-1}$ соответственно. Анализ экспериментальных данных с учетом вклада квантово-размерного эффекта, гидростатических деформаций решетки, вклада поверхностного фонона и рассеяния на частоте поверхностных плазмонов показывает, что в матрице $\mathrm{SiO}_{2}$ основной вклад в комбинационное рассеяние света вносят рассеяние на частоте оптических фононов деформированных $\mathrm{In}-\mathrm{Sb}$-связей за счет влияния гидростатического сжатия под давлением $\sim 10$ кбар и рассеяние, соответствующее резонансу Фрёлиха.

\section{2. Магнетронное напыление пленок $\mathrm{SiO}_{2}$ с нанокристаллами InSb}

Метод магнетронного радиочастотного напыления широко применяется для создания пленок оксида кремния с полупроводниковыми нанокристаллами. Особенность этого метода заключается в том, что осажденные пленки имеют низкую плотность по сравнению с термически выращенными пленками $\mathrm{SiO}_{2}$ [43]. С целью уплотнения таких осажденных пленок и улучшения их структурных и электрофизических свойств используют, как правило, быстрый термический отжиг (RTA) при температурах $>900^{\circ} \mathrm{C}$ или обычный печной отжиг при относительно низких температурах.

В работе [20] тонкая пленка $\mathrm{SiO}_{2}$ с наночастицами $\mathrm{InSb}$ была выращена на подложке $\mathrm{Si}$ с ориентацией (111) методом магнетронного распыления путем одновременного распыления кварцевой мишени и образцов InSb. Во время осаждения температура подложки Si поддерживалась $\sim 300^{\circ} \mathrm{C}$. Толщина осажденной пленки составляла $\sim 1$ мкм. Структурные свойства пленок изучались методами рентгеновской дифракции и мёссбауэровской спектроскопии. Сразу после осаждения в спектрах рентгеновской дифракции были четко видны пики, соответствующие направлениям (111), (220) и (311) в матрице монокристалла InSb, но смещенные в сторону бо́льших значений угла Брэгга по сравнению с его значениями в объемном материале. Рассчитанные из спектров средние размеры нанокристаллов InSb составили 30 нм. При этом из результатов анализа мёссбауэровской спектроскопии было установлено, что длина связи $\mathrm{In}-\mathrm{Sb}$ в нанокристалле практически совпадала с ее значением в монокристалле InSb. Но координационное число атомов первой оболочки $\mathrm{In}-\mathrm{Sb}$ в нанокристалле составляет 2.8 , в то время как в объемном кристалле это значение равно 4. Такое разупорядочение в нанокристалле $\mathrm{InSb}$ авторы связывают с вкладом структурного разупорядочения границы раздела $\mathrm{InSb} / \mathrm{SiO}_{2}$ за счет образования ковалентных $\mathrm{Sb}-\mathrm{O}$-связей.

В спектрах КРС, возбуждаемых линией Ar-лазера 514.5 нм в напыленных пленках, наблюдается широкая полоса рассеяния в диапазоне от $\sim 170$ до $\sim 190 \mathrm{~cm}^{-1}$, являющаяся суперпозицией двух полос с максимумами 178.3 и $188.0 \mathrm{~cm}^{-1}$, которые смещены в низкочастотную область на 1.1 и $2.5 \mathrm{~cm}^{-1}$ соответственно по отношению к частотам TO- и LO-фононов в объемном монокристалле InSb. Авторы [20] связывают наблюдаемое смещение с квантово-размерным эффектом в нанокристаллах $\mathrm{InSb}$ размером $\sim 30$ нм. Однако, как было показано в работах $[17,18]$ (рис. 3), квантово-размерный эффект в нанокристаллах с радиусом > 10 нм практически не наблюдается. Поэтому наблюдаемые смещения в частоте оптических фононов в работе [20] естественно связать с деформациями растяжения, которые могут присутствовать в осажденных пленках с низкой плотностью. Действительно, в работе [21] было обнаружено, что в магнетронно-осажденных пленках $\mathrm{SiO}_{2}$, содержащих $12.5 \% \mathrm{InSb}$, после быстрого термического отжига при температуре $900^{\circ} \mathrm{C}$ в течение 1 мин формировалась структура, соответствующая дифракционной картине кубической решетки в направлении (101) InSb. При этом параметр решетки составлял 0.6628 нм, в то время как соответствующий параметр решетки объемного монокристалла составляет 0.6461 нм [44]. Следует заметить, что для постоянной радиочастотной мощности толщина напыляемого слоя зависит от времени осаждения и условий последующей термообработки из-за явления уплотнения. Толщина пленок составляла $51 \pm 5$ нм до 
отжига и $\sim 41 \pm 4$ нм после RTA обработки при температуре $900^{\circ} \mathrm{C}$. Уплотнение пленки в данном случае происходит одновременно с ростом размеров нанокристаллов. Заметим, что при радиочастотном магнетронном распылении нанокристалл формируется уже в процессе осаждения пленки. Его плотность атомов, так же как и плотность самой пленки $\mathrm{SiO}_{2}$, может быть меньше плотности монокристалла InSb. При последующем отжиге возможно и изменение плотности нанокристалла, в том числе и в условиях его плавления. Однако в этом случае отсутствие сжимающей матрицы, как это было, например, при ионно-лучевом синтезе в работах $[17,18]$, не приводит при остывании к возникновению гидростатического сжатия решетки InSb. Наоборот, решетка остается растянутой.

В спектрах КРС, возбуждаемых линией 514.5 нм Arлазера в осажденных образцах после быстрого термического отжига при температурах $200-600^{\circ} \mathrm{C}$ в течение 1 мин, наблюдается лишь пик рассеяния на частоте $152 \mathrm{~cm}^{-1}$ [21]. Авторы [21] связывают его с рассеянием на частоте оптических фононов в кластерах $\mathrm{Sb}$ [30]. И лишь после RTA отжига при температуре $900^{\circ} \mathrm{C}$ в спектре наблюдался широкий пик с максимумом вблизи $180 \mathrm{~cm}^{-1}$ и асимметрией в высокочастотной области, который может быть суперпозицией пиков рассеяния, соответствующих TO- и LO-модам в нанокристаллах InSb. При длительных отжигах (1-4ч) при той же температуре $900^{\circ} \mathrm{C}$ линии, обусловленные рассеянием на фононах в матрице InSb, в спектрах КРС не наблюдаются. В этом случае основное рассеяние связано с оптическими фононами в кристаллической фазе $\mathrm{Sb}$ на частотах 115 и $152 \mathrm{~cm}^{-1}$. Интересно, что пики, связанные с активной формой индия, в этом случае не наблюдаются. Это означает, что индий при длительном отжиге либо растворяется в матрице оксида кремния, либо испаряется из нее.

\section{4. Заключение}

На основе анализа имеющихся литературных данных установлено, что свойства оптических фононов в нанокристаллах InSb зависят как от матрицы, в которой они синтезированы, так и от метода синтеза.

В спектрах КРС нанокристаллов InSb, ионно-синтезированных в матрице монокристаллического кремния с ориентацией (100), наблюдается лишь мода продольного оптического фонона LO. Отсутствие в спектрах поперечной (ТО) моды обусловлено ориентированным ростом нанокристаллов InSb в соответствии с решеткой (100) $\mathrm{Si}$ в которой поперечные оптические фононы запрещены правилами отбора. Частота основной LO-линии и еe ширина соответствуют их значениям в объемном монокристалле InSb, что является свидетельством отсутствия значительных деформаций в нанокристаллах.

В спектрах КРС нанокристаллов InSb, ионно-синтезированных в термически выращенных на кремнии плен- ках $\mathrm{SiO}_{2}$, наблюдаются обе моды (TO и LO) оптических фононов, поскольку нанокристаллы имеют произвольную ориентацию. Частоты оптических фононов в нанокристаллах сильно смещены в сторону больших значений, а расщепление TO-LO-моды при этом на $3 \mathrm{~cm}^{-1}$ меньше его значения в объемном монокристалле InSb. Наблюдаемые эффекты проанализированы с точки зрения влияния квантово-размерного эффекта, механических напряжений в нанокристаллах, частоты поверхностного фонона, а также рассеяния на частоте, соответствующей растянутым анион-катионным модам на поверхности полярных сферических нанокристаллов. Полученные результаты показывают, что в матрице $\mathrm{SiO}_{2}$ нанокристаллы InSb гидростатически сжаты при давлениях $\sim 10$ кбар. При этом в формирование спектров КРС большой вклад может вносить рассеяние, соответствующее резонансу на частоте Фрёлиха.

В спектрах КРС нанокристаллов InSb в пленках $\mathrm{SiO}_{2}$, осажденных методом магнетронного распыления, наблюдаются линии и TO-, и LO-фононов, но сдвинуты в область низких частот относительно их положения в объемном монокристалле InSb. Параметры TO- и LO-пиков зависят как от температуры осаждения, так и от условий последующего отжига. Осажденные пленки имеют низкую плотность атомов и низкочастотный сдвиг линий оптических фононов может быть обусловлен напряжениями растяжения связей $\mathrm{In}-\mathrm{Sb}$.

\section{Благодарности}

Авторы выражают благодарность проф. Ф.Ф. Комарову за любезно предоставленные для анализа оригинальные спектры КРС и А.Б. Талочкину за полезные обсуждения данных КРС.

\section{Финансирование работы}

Работа выполнена при поддержке Министерства образования и науки РФ (ГЗ 0306-2019-0005).

\section{Конфликт интересов}

Авторы заявляют, что у них нет конфликта интересов.

\section{Список литературы}

[1] H. Ko, K. Takei, R. Kapadia, S. Chuang, H. Fang, P.W. Leu, K. Ganapathi, E. Plis, H.S. Kim, S.-Y. Chen, M. Madsen, A.C. Ford, Y.-L. Chueh, S. Krishna, S. Salahuddin, A. Javey. Nature, 468, 286 (2010).

[2] A.C. Ford, C.W. Yeung, S. Chuang, H.S. Kim, E. Plis, S. Krishna, C. Hu, A. Javey. Appl. Phys. Lett., 98, 113105 (2011).

[3] K. Takei, R. Kapadia, H. Fang, E. Plis, S. Krishna, A. Javey. Appl. Phys. Lett., 102, 153513 (2013).

[4] S. Prucnal, Sh. Zhou, X. Ou, S. Facsko, M.O. Liedke, F. Bregolin, B. Liedke, J. Grebing, M. Fritzsche, R. Hubner, A. Mucklich, L. Rebohle, M. Helm, M. Turek, A. Drozdziel, W. Skorupa. J. Appl. Phys., 115, 074306 (2014). 
[5] C. Hilsum, A.C. Rose-Innes. Semiconducting III-V compounds, ed. by H.R. Henisch (Oxford-London-N.Y.-Paris, Pergamon Press, 1961) p. 254.

[6] R. Prasher, D. Dass, R. Vaid. J. Nano-Electron. Phys., 5, 01017 (2013).

[7] N.A. Viglin, V.V. Ustinov, S.O. Demokritov, A.O. Shorikov, N.G. Bebenin, V.M. Tsvelikhovskaya, T.N. Pavlov, E.I. Patrakov. Phys. Rev. B, 96, 235303 (2017).

[8] F.F. Komarov, O.V. Mil'chanin, L.A. Vlasukova, W. Wesch, A.F. Komarov, A.V. Mudryi. Bull. Rus. Acad. Sci. Phys., 74, 252 (2010).

[9] S. Prucnal, M. Turek, A. Drozdziel, K. Pyszniak, S.Q. Zhou, A. Kanjilal, W. Skorupa, J. Zuk. Appl. Phys. B, 101, 315 (2010).

[10] F. Komarov, L. Vlasukova, M. Greben, O. Milchanin, J. Zuk, W. Wesch, E. Wendler, A. Togambaeva. Nucl. Instr. Meth. Phys. Res. B, 307, 102 (2013).

[11] F. Komarov, L. Vlasukova, O. Milchanin, W. Wesch, E. Wendler, J. Zuk, I. Parkhomenko. Mater. Sci. Eng. B, 178, 1169 (2013).

[12] F. Komarov, L. Vlasukova, O. Milchanin, M. Greben, I. Parkhomenko, A.V. Mudryi, E. Wendler, P. Zhukowski. Acta Phys. Polon. A, 125, 1288 (2014).

[13] F.F. Komarov, I.A. Romanov, L.A. Vlasukova, O.V. Milchanin, I.N. Parkhomenko, T.B. Kovaleva, O.V. Korolik, A.V. Mudryi, E. Wendler. J. Appl. Spectrosc., 83, 959 (2017).

[14] I.E. Tyschenko, A.G. Cherkov, M. Voelskow, V.P. Popov. Solid State Phenomena, 131-133, 137 (2008).

[15] I.E. Tyschenko, M. Voelskow, A.G. Cherkov, V.P. Popov. Nucl. Instr. Meth. Phys. Res. B, 267, 1360 (2009).

[16] И.Е. Тысченко, М. Фельсков, А.Г. Черков, В.П. Попов. ФТП, 48, 1228 (2014).

[17] I.E. Tyschenko, V.A. Volodin, A.G. Cherkov, M. Stoffel, H. Rinnert, M. Vergnat, V.P. Popov. J. Luminesc., 204, 656 (2018).

[18] И.Е. Тысченко, В.А. Володин, В.П. Попов. ФТП, 53, 502 (2019).

[19] K. Zhu, J. Shi, Y. Wei, L. Zhang, Chin. Sci. Bull., 43, 1610 (1998).

[20] D. Chen, C. Li, Z. Zhu, J. Fan, S. Wei. Phys. Rev. B, 72, 075341 (2005)

[21] B. Capoen, V.Q. Lam, S. Turrel, L.P. Vilcot, F. Beclin, Y. Jestin, M. Bouazaoui. J. Non-Cryst. Sol., 351, 1819 (2005).

[22] K.G. Zhu, Y. Shaoqing, J.Z. Shi. Chin. Phys. Lett., 186, 779 (2001).

[23] D. Li, H. Li, H. Sun, L. Zhao. Nanoscale Res. Lett., 6, 601 (2011).

[24] S. Solmi, A. Parisini. J. Appl. Phys., 92, 1361 (2002).

[25] R.W. Olesinski, G.J. Abbaschian. Bull. All. Phase Diagr., 6, 445 (1985).

[26] R.N. Ghoshtagore. Phys. Rev. B, 3, 2507 (1971).

[27] R.N. Ghoshtagore. Phys. Rev. B, 3, 397 (1971).

[28] P. Madakson, E. Ganin, J. Karasinski. J. Appl. Phys., 67, 4053 (1990).

[29] S.Yi. Shiryaev, A.N. Larsen, M. Deicher. J. Appl. Phys., 72, 410 (1992).

[30] A. Roy, M. Komatsu, K. Matsushi, S. Onari. J. Phys. Chem. Solids, 58, 741 (1997).

[31] K. Aoki, E. Anastassakis, M. Cardona. Phys. Rev. B, 30, 681 (1984).

[32] J. Haisma, J.A. Pistorius, D. Mateika. J. Cryst. Growth., 102, 979 (1990).

[33] A.H. van Ommen. J. Appl. Phys., 57, 1872 (1985).
[34] A.H. van Ommen. J. Appl. Phys., 57, 5220 (1985).

[35] A.H. van Ommen. J. Appl. Phys., 56, 2708 (1984).

[36] A.H. van Ommen. J. Appl. Phys., 61, 993 (1987).

[37] В.П. Попов, И.Е. Тысченко. Патент РФ № 2217842. Бюл. № 33, 27.11.2003.

[38] I.H. Campbell, P.M. Fauchet. Sol. St. Commun., 58, 739 (1986).

[39] H. Richter, Z.P. Wang, L. Ley. Sol. St. Commun., 39, 625 (1981).

[40] V.A. Volodin, V.A. Sachkov. J. Exp. Theor. Phys., 116, 87 (2013).

[41] R. Ruppin, R. Englman. Rep. Progr. Phys., 33, 149 (1970).

[42] M.I. Vasilevskiy, A.G. Rolo, M.V. Artemyev, S.A. Filonovich, M.J.M. Gomes, Yu.P. Rakovich. Phys. Status Solidi B, 224, 599 (2001).

[43] W.K. Choi, C.K. Choo, K.K. Han, J.H. Chen, F.C. Loh, K.L. Tan. J. Appl. Phys., 83, 2308 (1998).

[44] Selected powder diffraction data for minerals, ed. by L.G. Berry (Data book. Swarthmore, Pennsylvania, Joint Committee on Powder Diffraction Standards, 1974) p. 833.

Редактор Г.А. Оганесян

\section{Structural properties and optical phonons in InSb nanocrystals synthesized in $\mathrm{Si}$ and $\mathrm{SiO}_{2}$}

\author{
I.E. Tyschenko ${ }^{1}$, R. Zhang ${ }^{2}$
}

${ }^{1}$ Rzhanov Institute of Semiconductor Physics,

Siberian Branch of Russian Academy of Sciences,

630090 Novosibirsk, Russia

${ }^{2}$ Novosibirsk State University,

630090 Novosibirsk, Russia

Abstract The interest in creating and studying silicon based $\mathrm{InSb}$ nanocrystals is motivated by producing hybrid integrated circuits involving elements with different functional properties. Localization of optical phonons in low-dimension crystals can affect both their optical and electrical properties. In this paper, a comparative analysis of the optical phonon properties in InSb nanocrystals ion-beam synthesized in silicon as well as in InSb nanocrystals produced in $\mathrm{SiO}_{2}$ layers by ion-beam synthesis and magnetron co-sputtering technique was performed. The properties of optical phonons in InSb nanocrystals are explained in terms of the influence of the surrounding matrix structural properties. 